\title{
Estudo Analítico de um Modelo de Competição para a Interação entre Espécies de Peixes
}

\section{Thyago Souza do Nascimento ${ }^{1}$}

Instituto de Ciência, Engenharia e Tecnologia, ICET, UFVJM, Teófilo Otoni, MG Ana Paula de Oliveira ${ }^{2}$

Instituto de Ciência, Engenharia e Tecnologia, ICET, UFVJM, Teófilo Otoni, MG José de Kalais Rebouças Santos ${ }^{3}$

Instituto de Ciência, Engenharia e Tecnologia, ICET, UFVJM, Teófilo Otoni, MG Jaqueline Maria da Silva ${ }^{4}$

Instituto de Ciência,Engenharia e Tecnologia, ICET, UFVJM, Teófilo Otoni, MG

Resumo. Este trabalho propõe um estudo do comportamento dos pontos de equilíbrio de um modelo de Lotka-Volterra modificado. O modelo trata da dinâmica de interação entre as espécies de peixes mais densas presentes na Usina Hidrelétrica de Santa Clara (UHSC),localizada no município de Nanuque-MG.

Palavras-chave. Modelos competitivos, interação, pontos de equilíbrio, populações.

\section{Introdução}

O estudo do comportamento dos pontos de equilíbrio em sistemas dinâmicos é de grande importância em modelagem matemática, principalmente no que diz respeito aos modelos de interação entre populações de espécies distintas. A UHSC foi construída no município de Nanuque no Vale do Mucuri e prejudicou a biodiversidade aquática existente na bacia hidrográfica do Rio Mucuri. Neste sentido,este trabalho apresenta um estudo sobre a estabilidade dos pontos de equilíbrio de um modelo de interação entre as populações de peixes presentes no lago da UHSC.

\footnotetext{
${ }^{1}$ thyago_msc@hotmail.com

${ }^{2}$ paula.mmm@hotmail.com

${ }^{3}$ kalaissantos@hotmail.com

4jaqueline.silva@ufvjm.edu.br
} 


\section{Modelo de competição com o esforço da pesca}

O modelo modificado de Lotka-Volterra apresentado neste trabalho tem parâmetros que consideram a variação da altura da àgua em função do tempo e a influência do esforço da pesca. É dado pelo seguinte sistema de equações diferenciais:

$$
\left\{\begin{array}{c}
\frac{d x}{d t}=x(a-E)-\alpha x y\left(\frac{1}{1+\eta \sin \left(\frac{2 \pi t}{365}\right)}\right) \\
\frac{d y}{d t}=-y(b+E)+\beta x y\left(\frac{1}{1+\eta \sin \left(\frac{2 \pi t}{365}\right)}\right)
\end{array}\right.
$$

Neste caso, $x$ e $y$ representam a população de presas e predadores, respectivamente; $a$ representa o crescimento das presas; $b$ a taxa de mortalidade dos predadores; $\alpha$ a mortalidade das presas; $\beta$ a taxa de conversão de biomassa das presas capturadas pelos predadores; $\eta$ o peso da variação do nível de água ao longo do tempo e $E$ o esforço de pesca.

\section{Resultados e Discussões}

Após o estudo dos autovalores, verificou-se que o ponto $P_{1}(0,0)$ é estável se $E>a$, ou instável se $E<a$. O ponto $P_{2}\left(\frac{(b+E)\left[1+\eta \sin \left(\frac{2 \pi t}{365}\right)\right]}{\beta}, 0\right)$ pode ser estável, assintoticamente estável ou instável se $E>a$ ou, instável se $E<a$. O ponto $P_{3}\left(0, \frac{(a-E)\left[1+\eta \sin \left(\frac{2 \pi t}{365}\right)\right]}{\alpha}\right)$ pode ser estável, assintoticamente estável ou instável. O ponto $P_{4}\left(\frac{(b+E)\left[1+\eta \sin \left(\frac{2 \pi t}{365}\right)\right]}{\beta}, \frac{(a-E)\left[1+\eta \sin \left(\frac{2 \pi t}{365}\right)\right]}{\alpha}\right)$ é estável se $\frac{-2 \pi \eta \cos \left(\frac{2 \pi t}{365}\right)}{365\left[1+\sin \left(\frac{2 \pi t}{365}\right)\right]^{2}}<0$ ou instável se $\frac{-2 \pi \eta \cos \left(\frac{2 \pi t}{365}\right)}{365\left[1+\sin \left(\frac{2 \pi t}{365}\right)\right]^{2}}>0$. Apenas $P_{4}$ representa a coexistência entre as espécies, sendo este, o mais representativo biologicamente e matematicamente. Os outros três pontos extinguem uma ou duas populações simultaneamente. Por outro lado, analisando as simulações computacionais do modelo, confirmou-se que $\eta$ e $E$ influenciam a dinâmica de interação entre as espécies. Verificou-se que conforme $\eta$ aumenta, a interação entre as espécies diminui em função do aumento do volume de água. Quanto maior o valor de $E$, mais as densidades das populações tendem a decair, o que dificulta a predação.

\section{Agradecimentos}

Agradecemos a FAPEMIG pela bolsa de iniciação científica de um dos autores.

\section{Referências}

[1] W. E. Boyce e R. C. DiPrima, Equações Diferenciais Elementares e Problemas de Valores de Contorno, LTC, (2006).

[2] M. Moreira, J. M. Silva e M. V. Kritz, Efeitos da variação da água e da pesca na interação entre peixes na Hidrelétrica de Santa Clara, um estudo de caso, XXXV CNMAC Congresso Nacional de Matemática Aplicada Computacional, (2014). 